\title{
Role of Smart Communication Technologies for Smart Retailing
}

\author{
Joshi Sujata, Parashar Mukul, Kaur Hasandeep
}

\begin{abstract}
The Indian retail industry is growing by leaps and bounds and currently ranks amongst the top 5 destinations for retail investment globally. Retailing is one of the pillars of the Indian economy. About 10\% of India's GDP comes from the retail industry. With the advent of digital transformation in the Indian economy and adoption of smart city initiatives, there is a need for the retail sector to shift from the traditional retailing to smart retailing. Smart technologies like Artificial Intelligence and Internet of Things are being used globally in the retail sector. But India is still lagging behind in this initiative. In academic literature, very few studies have focussed on the role of technologies in smart retailing. So the objective of this paper is to understand the role of smart technologies like AI and IOT and its impact on the retail sector. The study adopts the case study approach wherein various use cases from the retail sector have been analysed with respect to adoption of AI and IoT technologies and its benefit for smarter retailing. Potential technologies for smart retailing in the area of AI and IOT which can be applied in India have also been discussed. The study will be useful to the practitioners in the field of $A I$ and IoT technologies to create customized solutions for the retail sector; to the academicians as it adds to the literature on adoption of technology in retail sector; and the society at large will be benefitted as customers will get better delivery, better service and better customer experience.
\end{abstract}

Keywords - AI, IoT, Digitization, Smart Communication, Smart Retailing

\section{INTRODUCTION}

The global retail industry has expanded impressively despite the economic turbulence a decade ago and varying consumption patterns across the world. It was valued $\$ 23 \mathrm{bn}$ in 2017 and is expected to grow at CAGR 5.3\% by 2023 (Research and Markets , 2018). The developing economies of China, India and Latin America are the flag bearers of the growth scale of this industry. It is estimated that China can overtake the US as the world's largest consumer by the 2025-end followed by the UK, Japan and Germany [1].

The current state of affairs is the paradigm shift of retail from the regular retail store to the e-commerce channel. This has given the freedom of shopping however, wherever and whenever the customer demands which the standard brick and mortar retails stores could not provide. Today is the time of immense competition wherein the retail stores have to compete with the online stores [2]. The traditional business models need a transformative change to a better consumer experience and more innovative solutions to

Revised Manuscript Received on July 18, 2019.

Joshi Sujata, Professor, Symbiosis Institute of Telecom Management, constituent of Symbiosis International (Deemed University), Pune, India. (E-mail: sjoshi@sitm.ac.in)

Parashar Mukul, Student Symbiosis Institute of Telecom Management, constituent of Symbiosis International (Deemed University), Pune, India. (E-mail: mukul.parashar1820@sitm.ac.in)

Kaur Hasandeep, Student Symbiosis Institute of Telecom Management, constituent of Symbiosis International (Deemed University), Pune, India. (E-mail: hasandeep.kaur1820@sitm.ac.in) manage manpower, resources, margin and space productivity [3].

It is the age of smart cities, connected homes and autonomous cars and so the retail sector should not lag behind. The conversion of the retail sector into smart retailing is essential towards the overall development of a smart city. In this transformation, the AI and IoT based smart communication technologies play a pivotal role. The smart communication technologies are a synergy of AI and IoT which essentially turn a traditional retail store into a smart retail store [4]. AI and IoT will help retailers to reach the holy grail of personalization. Retailers can use these technologies to develop smart solutions for anticipating future purchases, guide shoppers, personalize products, automate processes, capitalize information gathered through smart devices, create economies of scale and manage repetitive tasks like answer routine queries [5].

There is an imminent need for the stores to get smart and enhance the shopping experience. This calls for a shift towards experience based retailing and the changes should be customer centric. AI and IoT based smart communication technologies can be leveraged to enable this push towards experience based smart retail stores .

Hence the objective of the paper is to understand the role of smart technologies like AI and IOT and its impact on the retail sector.

\section{LITERATURE REVIEW}

\subsection{Meaning of Smart Retailing}

Smart retailing is the emergence of an ecosystem of consumer centric retailing activities. Every activity in the value chain of retailing- including production and design, logistics and warehousing, centralized procurement, marketing, operations, services and management and cash flow- can be incorporated into a digitalized and intelligent platform. The business model is changing reflected by evolving operating models, data handling, marketing approaches and supply chain integration. Emerging technologies like artificial intelligence (AI), augmented reality (AR), virtual reality (VR), internet of things (IoT) and Big data analytics are becoming more sophisticated and integrated [6]. The combination of these smart technologies with retail to create autonomous outlets can be termed as smart retailing. At present, there are three main business forms in the unmanned retail industry, including unmanned convenience stores, open shelves and smart retail containers [7]. 


\subsection{Meaning of Smart Communication}

Internet systems and the advanced technologies have enabled communication systems to become 'smart'. Services modelled on open and standardized Internet protocols have transformed the ICT industry and delivered new business prospects leading to a massive raise in efficiency in the field of telecommunication and multimedia [8] Artificial intelligence is leveraged to formulate the insights gathered from numerous forms of communication (such as Wireless Sensor Network, Wireless Ad Hoc communication technologies (such as Device to Device, Machine to Machine, Sensor-Actuator), to understand the real time happenings of the system thus creating a smart communication system [9].

\subsection{Definition of Artificial Intelligence (AI)}

"Artificial intelligence (AI) is the simulation of human intelligence processes by machines, especially computer systems. These processes include learning (the acquisition of information and rules for using the information), reasoning (using rules to reach approximate or definite conclusions) and self-correction. Particular applications of AI include expert systems, speech recognition and machine vision" [10]. "Artificial intelligence (AI), the ability of a digital computer or computer-controlled robot to perform tasks commonly associated with intelligent beings. The term is frequently applied to the project of developing systems endowed with the intellectual processes characteristic of humans, such as the ability to reason, discover meaning, generalize, or learn from past experience" [10].

\subsection{Definition of Internet of Things (IoT)}

"The internet of things, or IoT, is a system of interrelated computing devices, mechanical and digital machines, objects, animals or people that are provided with unique identifiers (UIDs) and the ability to transfer data over a network without requiring human-to-human or human-tocomputer interaction" [11]. "The Internet of Things, commonly abbreviated as IoT, refers to the connection of devices (other than typical fare such as computers and smartphones) to the Internet. Cars, kitchen appliances, and even heart monitors can all be connected through the IoT. And as the Internet of Things grows in the next few years, more devices will join that list" [12].

\subsection{Studies Published in this Area and their relevance/gaps}

Drago, P [13] talks about the possibilities of implementing dynamic pricing in the retail industry and how the dynamic pricing, implemented by leveraging AI and IoT will benefit the retail industry. Meenakshi [14] in her paper talks about the importance of incorporating $\mathrm{AI}$ in the retail sector and how AI will enhance the consumer experience. Michael Azoff [15] talks about AI and IoT being the biggest trends to watch out for in the coming years. Ovum studied in-depth on how AI and IoT will be the future disruptors of the industry and change the retail space as we know it. R. Masoero et al, [16] in their published white paper talk about how the future of retail industry will be dictated by the IoT technologies. It also emphasizes on how the retail will be smarter and faster by incorporating IoT technologies. Jonathan Gregory [17] in his studies explains how the rapid Networks, Wireless Mesh Networks) over any type of

transformation is taking place in the retail industry and how IoT is playing a major role in revolutionizing the retail sector. Birla and Uniyal [18] in their study talk about the smart stores of the future. The study explores the various technologies which are leveraged to transform a traditional retail store into a smart one and how these technologies need to be implemented to make the retail experience faster and better. Mohapatra and V. Krishnan [19] in their study focus on how the customer experience matters and drives the sales in the retail industry and how the customer experience can be enhanced by leveraging AI and IoT based technologies. The study by Atos [20] explores how the future of in-store shopping will be like. It studies how the technologies will have an impact on the current retail stores and make them smart just like the e-commerce websites. Pavaluru [21] in his research paper talks about the future of shopping carts. The paper discusses in detail the technologies incorporated to convert the usual shopping cart into a smart e-kart and how it will enhance the user experience and drive numbers. Zhao and Li [7] in their paper talk about how the unmanned store has been beneficial for the operational aspects of the business and how it affects the efficiency of a retail store.

\section{RESEARCH METHOD}

A case study approach has been adopted for this study wherein various use cases in the retail sector have been analyzed with respect to the adoption of smart technologies like AI and IoT for smart retailing and the benefits accrued of the same to the discussed companies. The data for this study has been collected through various online databases, whitepapers, articles and reports. Collected literature was then analyzed for relevance to the topic.

The following were the research questions addressed through thus study:

1) Do smart communication technologies like AI and IoT play a significant role in smart retailing?

2) Are there specific use cases of adoption of AI and IOT technologies by companies for making their retail processes "smarter"?

\section{AI AND IOT TECHOLOGIES IN RETAIL: USE CASES}

\subsection{Use case 1:Amazon Go}

Introduced in 2016 and head quartered in United States, Amazon Go is a chain of convenience stores operated by ecommerce giant Amazon. Amazon runs four Go stores in its hometown of Seattle, four in Chicago and three in San Francisco (Amazon, 2017). The stores are partly automated with walk-out check-out points and the customers are tracked and billed accordingly and automatically [22]

\subsubsection{Technologies Adopted}

The system of Amazon Go backs majorly on sensory fusion, deep learning algorithms and computer vision. It uses technologies like artificial intelligence, machine learning, IOT, integrated payments, advanced QR code ID's, image recognition, multiple sensor technology and a 
powerful app which uses GPS [23]. There are more than 100 cameras over an 1800 sq. ft. store in the Seattle; and Amazon Go is well equipped to see and identify every item in the store without assigning a distinct chip to every can of soup and packet of salad [24,26].

\subsection{Benefits Accrued}

The Amazon Go stores are successful in providing a frictionless shopping experience with their "Just Walk out Technology" to the customers. There are no queues at the check-out and the amount gets deducted from your amazon account automatically. However, the major benefit fetched out of these technologies is the data so collected from these stores which will prove to be a major breakthrough in the retail industry as the data collected by the cameras will help find answers to the big enigma of why does a customer buy, what causes someone to pick something off the shelf, put it in the basket and pay for it [25].

\subsection{Use Case 2: Zippin}

Zippin is a start-up based out of San Francisco which started as a product-tracking technology company in 2014. Today, it is a convenience store running at San Francisco with automated check-out points. The aim is to revolutionise the standard check-out system to save time and add convenience.

\subsubsection{Technologies Adopted}

Zippin uses a combination of overhead cameras and sensors on the stores shelves, along with its AI-driven software and geometric computer vision to follow every customer's move in the retail store. Cameras use deep learning algorithms to track and hand-off the customers to another camera as they walk around the store. The store uses variety of sensors which include a combination of cameras, pressure, weight, infrared, acoustic etc. The AI system runs on commodity computers that are optimized to run deeplearning models on the edge with very low bandwidth. The images are processed on site and the sensor fusion takes place on the cloud [27].

\subsubsection{Benefits Accrued}

The goal of these stores is to assign the product picked and charge the right people without a customer or store associate and the need to scan while leaving the store. The creation of this experience comes along with additional benefits such as real-time inventory updates to the seller, ease of restocking the inventory, behavioral tracking of the customers to better for detailed analytics and lower operating costs due to cut down on manpower. The invaluable experience of shopping will eventually lead to increased sales and high customer satisfaction which is very important in today's scenario of high competition [27].

\subsection{Use Case 3: JD.ID X-Mart}

JD.ID X-Mart is a chain of convenience stores in China and Indonesia operated by online retailer JD.com. The first store was launched in 2017 in Beijing. The stores are powered to offer unprecedented level of convenience and a frictionless shopping experience to the customers.

\subsubsection{Technologies Adopted}

The unmanned stores of China's retail giant JD.Com are operated with the cutting-edge technologies of QR codes, facial recognition, RFID tags and image recognition that helps to trajectory the retail activity. There are cameras on the ceiling to recognise customer movements and generate heat maps of the activities taking place in the store to monitor consumer movement and product selection [28].

The JD smart vision technology with smart shelving tools aids to recognise products.

\subsubsection{Benefits Accrued}

The smart retail stores of JD. Com with its AI solution helps the store managers to measure and manage inventory and products in a better way. JD. Com has partnered with Intel and the future of retailing with strengths of these two combined will develop cutting-edge solutions to bring the precision of online shopping to offline stores. By leveraging JD's big data analysis capabilities and Intel's advanced edge computing technologies, the companies will build a more sophisticated retail ecosystem and enable the wider marketing of new commodities and technologies as well as facilitate their entry at global platforms [28].

\subsection{Use Case 4: Watasale}

Watasale is India's first fully automated AI based Retail Store, founded in September 2018 by Navasale Private Limited. Watasale is the dream project of five people coming from retail and technology backgrounds. It took three years of brainstorming to officially launch the store. Major challenges faced by the company were to find the apt human resources for this cutting-edge technology. The founders created a strong team of professionals who were trained in deep learning and AI techniques [29].

\subsubsection{Technologies Adopted}

To come up with a hassle-free shopping solution for customers Watasale, an automated AI based retail store was born. It is a combination of technologies like touch sensors, AI and computer vision. This outlet aims to change the entire user experience of going to a retail store and purchasing items sans a queue for billing.

The entire shopping experience with Watasale is very quick and smooth. It involves the customers downloading their application and scanning the QR code generated to enter the store. Then they just need to keep collecting the items they need and once finished with the shopping, can simply walk out of the store. The bill generated would reach on the shopper's handset and payment can be done with the help of debit or credit card or through mobile wallets [30].

\subsubsection{Benefits accrued}

AI-based systems have a host of other benefits as well, one of the most important being reducing frauds. In the cases of fraud and shoplifting, the product would still be billed even if the customer tries to hide it. As the system works on computer vision technology it ensures that whatever it was taken from the products racks are billed [31] 
Deep learning becomes critical when automation of a variety of processes is required. Autonomous warehouses use the same technology at a larger scale. The workflow processes consist of pressure sensors, RFID's, cameras for visual analytics etc. The Activity flow designed uses all the devices to provide an autonomous experience [31].

\subsection{Use Case 5: Feneberg Lebensmittel GmbH}

Feneberg Lebensmittel $\mathrm{GmbH}$ is a family-owned chain of supermarkets in Germany. Founded in 1947, it ventured into building branches in 1950 and by 2019; Feneberg operated 76 branches in Germany. The management is devoted towards the high quality products and the best customer service and store experience for its customers. This vision of management called for adoption of a better check-out system at their stores and hence the company tired up with Zebra Technologies [32].

\subsubsection{Technologies Adopted}

The store adopted an IoT based solution at their point-ofsale i.e. check out point to fasten the process of scanning and billing the products to save customer time and add to a convenient shopping experience. The durable and highperformance 2D barcode scanners are used at bakeries, butchers and flower shops. These scanners are named DS4208 Handheld 2D Imagers and DS9208 Omnidirectional Hands-free Presentation Imagers. Furthermore, MP6000 Multi-Plane 1D/2D Bi-optic Imagers are other products which scan and weigh the product simultaneously and covers the zone hundred per cent from six sides.

\subsubsection{Benefits accrued}

The major benefit radiated out of these scanners is that the product which is subject to be scanned need not be fully aligned while scanning which saves ample of time at the check-out points. The scanning is accurate and reliable so as not to miss any article. The ease of use improves efficiency of the workers. Moreover, it is a flexible technology and can easily be molded according to the future needs.

\section{6: Use Case 6: Hershey's}

Hershey's is a global leader of the confectionery industry with more than 80 brands across the globe. Created in 1909, the company is committed to operate fairly and focuses to grow its presence in the key international markets. With more than $\$ 7.4 \mathrm{bn}$ revenue stream, the company moves towards the integration of upcoming technologies with its regular stores.

\subsubsection{Technologies Adopted}

The Company uses a smart shelf technology provided by AWM Smart shelf that involves the heavy usage of highdefinition optical sensors and edge displays that will display the product pricing and will communicate about the inventory levels in the store. This technology is mature enough to recognise the customer's age and gender if more specific content is required [33]

\subsubsection{Benefits accrued}

This technology was implemented to transform a candy aisle to aid the shoppers to easily navigate the shelves majorly by playing with the colors of the chocolate packaging. The underlying benefit of the adoption of this technology is the track of inventory which can now be kept so as to utilize the manpower of the retail store towards better customer and retailer satisfaction [34].

\section{FUTURE APPLICATION \& RESULTS}

The retail industry has experienced noteworthy revolution over the past decade and it continues to advance quickly. The change has become possible on account of emerging technologies and evolving consumer behaviour. Today, the integrated network technologies are no more exclusive factors but are preconditions for future technologies. The new emerging forces of Internet of Things, Artificial Intelligence, Augmented/ Virtual Reality and robots will define the new direction of innovation. [35]

The retailers of future will have to address to three critical issues of; the smart use of Omni-channels, the experience for the customer and retailer's relationship with that customer's movements in the market. [35]

The most phenomenal of smart retail is yet to come. The smart technologies which will transform the retail into an experience-based retailing will come with their own special benefits. The technology of virtual mannequin, hologram customisation, mobile mirrors and magnetic RFID enabled POS system are the future trends. The adoption of virtual mannequins will help the retailer to cut costs and improve efficiencies by redeployment of staff, completely customise the solutions and provide as an interactive tool to customers. Hologram customisation will allow the customers to customise the design of the product and hence allow the retailer to solve the problems of customer satisfaction and inventory management. Mobile mirrors will support the apparel industry significantly by increasing convenience level in the shopping process. This technology allows seeing a 360-degree view of oneself featuring time delay display. RFID enabled POS system will help to manage theft issues and mass inventory management by speedy scanning of all the articles in the store.

Internet of Things, Artificial Intelligence, big data, and deep learning algorithms will form the base of these technologies. The consumer landscape is incredibly diverse and there are endless opportunities for retailers to experiment. The connected devices will recognise the customers; deep learning will understand their behaviour and Artificial Intelligence will provide better solutions.

\section{CONCLUSION AND FUTURE RESEARCH DIRECTIONS}

The push for a smart shopping ecosystem is on the cards as we can conclude from the above study that it is the need of the hour and the growing trend all across the globe. Use of smart communication technologies like AI and IoT in the context of smart retailing is the need of the hour.

From various studies, we can conclude that the main benefits from converting the retail stores into smart stores are the enhanced customer experience, ease of shopping, better maintenance, better supply chain management,

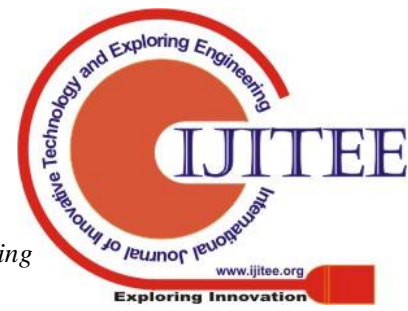


enhanced security and overall a faster, smarter and more delightful way of shopping. The smart communication technologies enhance both the operational experience on the retailer's side and the shopping experience on the customer's side.

The smart vision technology, facial recognition, magnetic smart communication technologies which can and should be implemented in Indian retail stores to transform them into smart stores.

There is a need to do research in terms of the impact of AI and IoT technologies in the specific areas of customer experience, supply chain management, inventory management and other marketing functions. Also a similar study can be done in areas other than marketing such as Infrastructure management, Financial Management, IT management etc.

\section{REFERENCES}

1. A.V. Kapoor and P. Khanna, "Analysis of Global Retail Industry: An Overview of Changing Trends" International Journal of Research in IT and Management, Vol 6, Issue 12, December-2016, pp 73-78, 2016. Available online at http://euroasiapub.org (Accessed on $13^{\text {th }}$ May 2019)

2. Beecham Research, "The Future of Retail through the Internet of Things," 2016. [Online] Available: https://www.intel.com/content/dam/www/public/us/en/docum ents/white-papers/future-retail-through-iot-paper.pdf (Accessed on $13^{\text {th }}$ May 2019)

3. Delloite, "2019 Media \& Entertainment Industry Outlook," 2018. [Online]. Available: https://www2.deloitte.com/us/en/pages/technology-mediaand-telecommunications/articles/media-and-entertainmentindustry-outlook-trends.html (Accessed on $13^{\text {th }}$ May 2019)

4. S.G. Tzafestas, "Synergy of IoT and AI in Modern Society: The Robotics and Automation Case," Robotics and Automation Engineering Journal, Volume 3, Issue 5, September 2018. Available: file:///C:/Users/HPPC/Downloads/Synergy_of_IoT_and_AI_in_Modern_Society $\% 20$ (3).pdf (Accessed on $13^{\text {th }}$ May 2019)

5. Retail Trends, "Global Retail Trends 2018", [Online]. Available: retail-trends-2018.pdf (Accessed on $13^{\text {th }}$ May 2019)

6. A T Kearney Report, "China's Smart Retailing Pays Off," [Online]. Available: https://www.atkearney.com/documents/20152/1332492/China s+Smart+Retailing+Pays+Off.pdf/c16fafc1-6a37-60aa-3ac2$25 \mathrm{dd} 63 \mathrm{dc} 5 \mathrm{fac}$ (Accessed on $13^{\text {th }}$ May 2019)

7. Lei Zhao, and Lefei Li," Analysis of Operational Benefits of Unmanned Retail Business Form based on DEA Method". Advances in Economics, Business and Management Research, volume 68, pp 109-113, 2018. [Online]. Available: file:///C:/Users/HP-PC/Downloads/SSMI123\%20(1).pdf.

(Accessed on $13^{\text {th }}$ May 2019)

8. C. Wietfeld, J. Schmutzler, \& C. Hägerling, "A Smart Communication Infrastructure for Future Energy System Applications". Future Internet Symposium 2009 International Workshop on the Future Internet of Things and Services - Embedded Web Services for Pervasive Devices. [Online]. Available: file:///C:/Users/HPPC/Downloads/A_Smart_Communication_Infrastructure_for_ Future_En.pdf (Accessed on $13^{\text {th }}$ May 2019)

9. J. Lloret, A. Canovas, S. Sendra, and L.Parra, "A Smart Communication Architecture for Ambient Assisted Living. Communications Magazine", IEEE. 53. 26-33. 10.1109/MCOM.2015.7010512. S. C. Lloret, "A Smart Communication Architecture for Ambient Assisted Living," RFID tags and common channel integration are some of the

https://assets.kpmg/content/dam/kpmg/xx/pdf/2018/03/global-

January 2015. [Online]. Available: file:///C:/Users/HPPC/Downloads/AsmartcommunicationarchitectureforAALv6. pdf (Accessed on $13^{\text {th }}$ May 2019)

10. B. Cooperland, "Artificial intelligence", May 2019. [Online] Available: https://www.britannica.com/technology/artificialintelligence (Accessed on $13^{\text {th }}$ May 2019)

11. M. Rouse, "Internet of things (IoT)", March 2019. [Online]. Available:

https://internetofthingsagenda.techtarget.com/definition/Intern et-of-Things-IoT (Accessed on $13^{\text {th }}$ May 2019)

12. A. Meola, "What is the Internet of Things (IoT)? Meaning \& Definition,"May 2018 [Online]. Available: https://www.businessinsider.com/internet-of-thingsdefinition?IR=T (Accessed on $13^{\text {th }}$ May 2019)

13. Drago Pupavac, "DYNAMIC PRICING: THE FUTURE OF RETAIL BUSINESS," 16th International Scientific Conference Business Logistics in Modern Management, pp 119-128, October 2016. [Online]. Available: http://blmmconference.com/wp-content/uploads/blimm1608.pdf (Accessed on $13^{\text {th }}$ May 2019)

14. Meenakshi Nadimpalli, Artificial Intelligence - Consumers and Industry Impact". International Journal of Economics \& Management Sciences. 06. 10.4172/2162-6359.1000429. January [Online]. Available: file:///C:/Users/HP PC/Downloads/Artificial_Intelligence_-

CConsumers_and_Industry_I.pdf (Accessed on $13^{\text {th }}$ May 2019)

15. Michael Azoff, " 2017 Trends to Watch: Artificial Intelligence". [Online]. Available: https://ovum.informa.com/ /media/Informa-Shop-

Window/TMT/Files/Whitepapers/2017-trends-to-watch-inAI.pdf (Accessed on $13^{\text {th }}$ May 2019)

16. R. Masoero, S. Buono, L.Malatesta, "Internet of Things: The Next Big Opportunity for Media Companies" 2017. [Online] Available:

https://www.accenture.com/t20180529T062413Z_w__usen/_acnmedia/PDF-50/Accenture-IoT4-POV-Updated.pdf (Accessed on $13^{\text {th }}$ May 2019)

17. Jonathan Gregory, "The Internet of Things: Revolutionizing the Retail Industry" 2015. [Online]. Available: https://www.accenture.com/_acnmedia/Accenture/Conversion

Assets/DotCom/Documents/Global/PDF/Dualpub_14/Accent ure-The-Internet-Of-Things.pdf (Accessed on $13^{\text {th }}$ May 2019)

18. A. Birla and G. Uniyal. "The smart store of the futurepowered by faster, cheaper and efficient IT" 2018. [Online]. Available: https://www.infosys.com/industries/retail/whitepapers/Documents/stores-digitally-mobile-wireless.pdf (Accessed on $13^{\text {th }}$ May 2019)

19. B. Mohapatra and V. Krishnan, "Customer experience for retail Industry," 2018. [Online]. Available: https://www.infosys.com/Oracle/white-

papers/Documents/customer-experience-retail-industry.pdf (Accessed on $13^{\text {th }}$ May 2019)

20. Atos, "The Future of In-store shopping," 2013. [Online]. Available: https://atos.net/wpcontent/uploads/2017/10/01122013-AscentWhitePaperFutureInStoreShopping.pdf (Accessed on $13^{\text {th }}$ May 2019)

21. Pradeep Pavaluru, "From Shopping Cart to SMART Kart"," 2017. [Online]. Available: https://www.evry.com/globalassets/india/what-we-do/retail-logistics/smart-kart---white-paper/smart-kart---whitepaper.pdf (Accessed on $13^{\text {th }}$ May 2019)

22. Amazon Go, 2017. [Online]. Available: https://www.amazon.com/b?node $=16008589011 \quad$ (Accessed on $13^{\text {th }}$ May 2019) 
23. A. Polacco and K. Backes, "THE AMAZON GO CONCEPT: IMPLICATIONS, APPLICATIONS, AND SUSTAINABILITY 2017. [Online]. Available: http://wdsinet.org/Annual_Meetings/2017_Proceedings/CR\% 20PDF/cr215.pdf (Accessed on $13^{\text {th }}$ May 2019)

24. Blake Ives, Kathy Cossick, and Dennis Adams, “Amazon Go: Disrupting retail?" 2019. Journal of Information Technology Teaching Cases 2019, Vol. 9(1) 2-12, https://doi.org/10.1177/2043886918819092 (Accessed on $13^{\text {th }}$ May 2019)

25. Knowledge@Wharton,"Will Amazon Go Capture the Holy Grail of Retail," 2018. [Online]. Available: https://knowledge.wharton.upenn.edu/article/amazon-gogame-changer/ (Accessed on $13^{\text {th }}$ May 2019)

26. N. Wingfield, "Inside Amazon Go, a Store of the Future," January 2018. [Online]. Available: https://www.nytimes.com/2018/01/21/technology/insideamazon-go-a-store-of-the-future.html (Accessed on $13^{\text {th }}$ May 2019)

27. M. Agrawal [Online]. "The State of Retail: It's Time for Change", Available: https://www.getzippin.com/hubfs/Future\%20of\%20Retail_Zip pin.pdf

28. Technology, "JD.COM AND INTEL LAUNCHNEW RESEARCH LAB FOR SMART RETAIL”, 2017. [Online]. Available: https://jdcorporateblog.com/jd-com-and-intellaunch-new-research-lab-for-smart-retail/ (Accessed on $13^{\text {th }}$ May 2019)

29. V. Verma, "Watasale, India's first autonomous retail store, opens in Kochi, gets funding offer from Japan," September $2018 . \quad$ [Online]. Available: https://indianexpress.com/article/technology/tech-newstechnology/watasale-indias-first-autonomous-retail-storeopens-in-kochi-gets-funding-offer-from-japan-5341884/ (Accessed on $13^{\text {th }}$ May 2019)

30. D. Tom and S. Karun, "App, swipe, go: This cashier-free store shows future of India," September 2018. [Online]. Available: https://timesofindia.indiatimes.com/india/app-swipe-go-thiscashier-free-store-shows-future-of-indianretail/articleshow/65747132.cms (Accessed on $13^{\text {th }}$ May 2019)

31. A. Menon, "Is Kochi's Watasale store the future of retail?" September 2018. [Online]. Available: https://www.thehindu.com/sci-tech/technology/is-kochiswatasale-store-the-future-of-retail/article24862249.ece (Accessed on $13^{\text {th }}$ May 2019)

32. Zebra, "German Supermarket Chain Modernises Its Systems with Zebra Technologies," 2015. [Online]. Available: https://www.zebra.com/content/dam/zebra/success-stories/enus/pdfs/feneberg-en-us.pdf. (Accessed on $13^{\text {th }}$ May 2019)

33. M.Thomas, "NO CHECKOUT LINES, PERSONALIZED SHELVING AND THE IOT RETAIL REVOLUTION," April 2019. [Online]. Available: https://builtin.com/internetthings/iot-in-retail-tech-applications (Accessed on $13^{\text {th }}$ May 2019)

34. Hershey, "TRANSFORMING THE CANDY AISLE EXPERIENCE”, 2018. [Online]. Available: https://www.thehersheycompany.com/en_us/blog/transformin g-the-candy-aisle-experience.html (Accessed on $13^{\text {th }}$ May 2019)

35. D.Grewal ${ }^{\mathrm{a}}$, an L.Roggeveen a, J. Nordfält , "The Future of Retailing", Journal of Retailing Volume 93, Issue 1, Pages 16, March 2017, [Online]. Available: https://doi.org/10.1016/j.jretai.2016.12.008 (Accessed on $13^{\text {th }}$ May 2019) 